\title{
FRAMEWORK TANGGAP BENCANA KEBAKARAN GEDUNG KAMPUS
}

\author{
Heru Sufianto ${ }^{1}$, Agung Murti Nugroho ${ }^{2}$, M Satya Aditama $^{3}$ \\ ${ }^{1}$ Jurusan Arsitektur, Fakultas Teknik Universitas Brawijaya Malang \\ ${ }^{2}$ Jurusan Arsitektur, Fakultas Teknik Universitas Brawijaya Malang \\ ${ }^{3}$ Jurusan Arsitektur, Fakultas Teknik Universitas Brawijaya Malang \\ Jl. Jl. MT Haryono No. 167 Malang
}

\begin{abstract}
Fires in buildings have significant impact on communities both socially and economically. In education facilities, fire incidents have potential impact on research product lost. Fire authorities, practitioners and relevant bodies have been addressed this issue partially on the points of physical aspects and management addressed to fire safety. This study seeks the importance element of a framework that should be implemented comprehensively increasing building fire protection around the clock. Physical assessment on numbers of buildings have been performed, a questionnaire seeking for occupant's awareness and knowledge toward fire incidents have been disseminated. Meanwhile, fire disaster models from a number of campuss buildings have been reviewed. The study found 4 elements of the fire disaster framework to be considered, including: the occupant's fire awareness, means of the building, insentives, and control.
\end{abstract}

Keywords: fire safety management, fire protection, building occupants, fire safety awareness.

\section{PENDAHULUAN}

Kebakaran gedung dapat terjadi pada setiap jenis peruntukkan bangunan, baik hunianpermukiman, perkantoran maupun fasilitas pendidikan. Di Indonesia, beberapa bangunan kampus (pendidikan) terjadi dalam kurun sepuluh tahun terakhir. Kebakaran yang terjadi di Kampus Universitas Islam Malang adalah kejadian kebakaran kampus terbaru (Juni 2016) yang diduga akibat hubungan arus pendek di panel listrik. Peristiwa tersebut menghanguskan 2 dari 3 lantai gedung yang ada dan menghabiskan ruangan beberapa laboratorium dan seisinya.

Kebakaran fasilitas pendidikan juga terjadi di Universitas Budi Luhur, Tangerang (Desember 2015) dimana kejadian tersebut terjadi pada saat jam perkuliahan berlangsung. Peristiwa tersebut menimbulkan kepanikan yang luar biasa. Penyebab timbulnya api diperkirakan dari hubungan arus pendek di salah satu ruang kuliah. Kebakaran hebat juga melanda Gedung Institut Bisnis dan Informatika Indonesia (IBII) atau yang lebih dikenal Kwik Kian Gie School of Business (Januari 2014). Peristiwa di siang hari tersebut mengakibatkan kepanikan mahasiswa berhamburan keluar ke halaman gedung, Api diduga berasal dari korsleting listrik alat pendingin udara. Di tahun yang sama kebakaran hebat juga terjadi pada gedung Fisip Universitas Indonesia. Walaupun tidak menimbulkan korban jiwa, kerugian kebakaran pada pusat kajian sosiologi tersebut tidak terlinai harganya, berbagai karya penelitian dan disertasi musnah. Penyebab kebakaran adalah hubungan arus pendek listrik.

Kebakaran kampus bukan hanya terjadi di Indonesia, peristiwa tersebut juga sering terjadi di beberapa universitas di Amerika. Tercatat mulai tahun 2000 hingga 2015, telah terjadi 85 peristiwa kebakaran kampus, atau rata-rata 7 kebakaran kampus per tahun yang keseluruhan memakan 118 korban jiwa. Sejumlah 58\% kejadian kebakaran yang memakan korban jiwa berasal dari gedung asrama, tempat berkumpul mahasiswa yang alat deteksi asapnya tidak bekerja (rusak), sedangkan $85 \%$ kejadian 
berkorban jiwa terjadi pada gedung yang tidak dilengkapi dengan peralatan sprinkler kebakaran.

Penyebab kebakaran dapat beragam, namun dapat dikategorikan kedalam dua aspek yaitu kecerobohan manusia dan gagalnya sistim 'engineering' bangunan. Kedua aspek tersebut bekerja baik pada saat perencanaan, pelaksanaan konstruksi maupun operasional bangunan (pasca huni). Di Indonesia kegagalan sistim engineering lebih tinggi, khususnya kegagalan sistim kelistrikan di dalam bangunan, misalnya: hubungan arus pendek listrik (Sufianto and Green, 2012).

Mekanisme kontrol regulasi terhadap keamanan bangunan dari bahaya kebakaran baru (fire protection system) pada tahapan perencanaan bangunan pada saat ini sudah berjalan (PU Cipta Karya, 2000), namun peristiwa kebakaran bangunan gedung masih sering terjadi. Hal ini dimungkinkan akibat lemahnya aspek pengawasan kinerja sistim engineering tersebut pada saat pengoperasian bangunan, terutama pengawasan pada gedung yang telah mengalami modifikasi fisik, pengembangan luasan ataupun pengalihan fungsinya. Beberapa kejadian kebakaran menunjukkan bahwa implementasi sistim engineering pada tahap perencanaan bangunan tanpa dukungan perbaikan pada aspek manusia-nya ternyata tidak menjamin terhindarnya bangunan dari bahaya api. Masih dibutuhkan suatu mekanisme kontrol yang efektif untuk mencegah percikan api sedini mungkin, mengisolir dan memadamkan percikan api sebelum api berkembang ke seluruh bangunan. Mekanisme penanganan bencana kebakaran juga dibutuhkan untuk memulihkan gedung agar dapat berfungsi seperti kembali dalam waktu sesingkat mungkin (fast building recovery). Keberadaan sistim manajemen tanggap kebakaran dibutuhkan untuk menutup kelemahan sistim engineering tersebut.

Universitas Brawijaya (UB), salah satu dari lima universitas besar di Indonesia memiliki kebijakan untuk mengembangkan gedungnya secara vertikal, hal ini dikarenakan keterbatasan lahan yang tersedia (58 Ha) dan jumlah penghuninya yang meningkat setiap tahunnya (sekitar 16.000 mahasiswa baru/ tahun). Saat ini terdapat lebih dari 16 gedung tingkat tinggi di kampus tersebut yang membutuhkan performa tinggi sistim penanggulangan kebakarannya baik sistim pencegahan maupun pemadamannya. Penelitian ini bertujuan membuat suatu framework atau model manajemen kebakaran untuk mengurangi kemungkinan terjadinya kebakaran di kampus UB dan mengurangi dampak yang timbul bila terjadi kebakaran gedungnya.

\section{Fire Safety Framework}

Menajemen keselamatan kebakaran pada dasarnya bertujuan untuk menjamin kesiapan bangunan dan penghuninya untuk mencegah terjadinya kebakaran dan mencegah tingkat kerugian/ resiko pada nilai yang dapat diterima oleh suatu manajemen gedung (Chen, Chuang, Huang, Lin, \& Chien, 2012; Hassanain \& Mohammed Abdul, 2005; Malhotra, 1993).

Pada tahap desain, manajemen keselamatan kebakaran yang digunakan untuk memastikan penyediaan tingkat keselamatan kebakaran melalui kesepakatan terhadap standar tertentu. Beberapa standar internasional baru-baru ini digunakan dalam bidang teknik keselamatan, termasuk: Pendekatan Rasional Rekayasa Keselamatan Kebakaran Gedung oleh CIB tahun 2001 dan Teknik Panduan untuk Aplikasi Penilaian Resiko Kebakaran oleh SFPE 2005

Pedoman pertama diprakarsai oleh Concil International du Batiment (CIB, juga dikenal sebagai Dewan Internasional untuk permasalahan bangunan) yang diarahkan untuk membantu semua pihak yang berkepentingan, termasuk regulator, arsitek, insinyur desain, dan perusahaan konstruksi, untuk meningkatkan mereka pemahaman tahan api dan metode dalam menilai desain keselamatan kebakaran dalam bangunan (CIB, 2001). Pedoman teknik ini dirancang melalui pendekatan berbasis kinerja (performance base). Bidang kerja pada pedoman keselamatan kebakaran ini dikelompokkan menjadi tiga bagian, yaitu bagian penentuan batasan tugas (task definition), analisis (analysis), dan dokumentasi (documentation) yang masing-masing mencakup sejumlah prosedur (Gambar 1). Pedoman tersebut mengadopsi prinsip manajemen resiko dimana tahapan definisi tugas (task definition) berfungsi untuk mengkonfigurasi konteks kerja secara keseluruhan, tahap analisis merupakan proses penilaian dan evaluasi, sementara dokumentasi meliputi instrumen untuk monitoring dan kontrol sebagai bahan untuk 
evaluasi tingkat keberhasilan dari tahap pertama. Bagian pertama terdiri 6 langkah, mendefinisikan konteks desain, tujuan, kriteria penerimaan dan desain sidang awal. Pada bagian kedua, desain awal diuji melalui alat rekayasa yang disepakati. Hanya ketika hasil yang dianggap memenuhi kriteria penerimaan yang diatur, bagian ketiga dilakukan, dokumentasi desain keselamatan kebakaran yang dipilih.

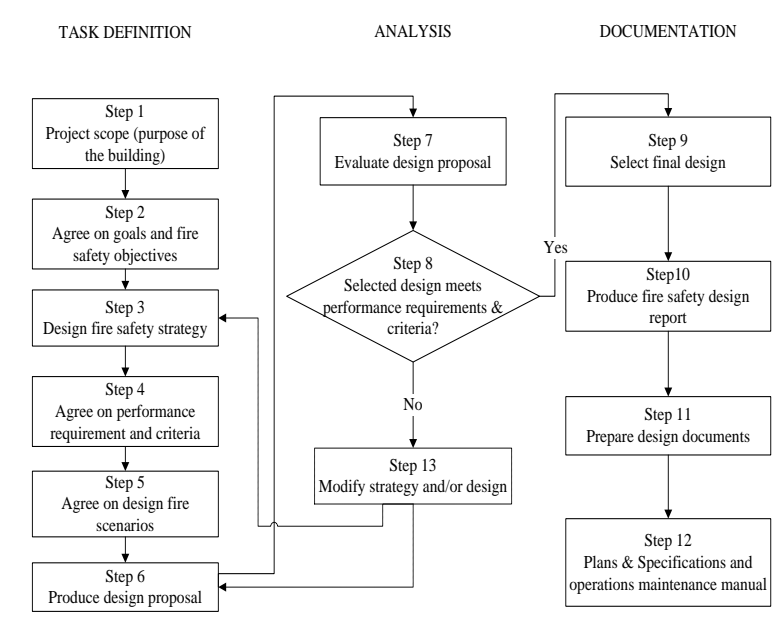

Gambar 1. Fire Safety Design Framework menurut CIB guideline (CIB, 2001)

Salah satu pedoman keselamatan kebakaran diperkenalkan oleh Society of Fire Protection Engineers (SFPE) berjudul 'SFPE Fire Risk Assessment Framework'. Pedoman ini memberikan arahan sistematis untuk teknisi yang berkualitas untuk berlatih teknik proteksi kebakaran. Bagi para pemangku kepentingan panduan berguna untuk menerapkan metodologi perkiraan resiko dalam desain keselamatan kebakaran dan analisis (SFPE, 2005). Pedoman ini juga memberikan bantuan pada peran penilaian resiko kebakaran dalam spektrum yang lebih luas dari manajemen resiko.

Prosedur penilaian resiko muncul dalam tiga tahap berurutan mengandung pengembangan konteks dan identifikasi bahaya dalam lima langkah pertama dari penilaian resiko dalam 4 langkah berikut, dan diikuti dengan dokumentasi untuk monitoring, review dan implementasi pada langkah akhir (Gambar 2). Pedoman ini muncul lebih komprehensif dibandingkan sebelumnya, memiliki proses yang lebih menyeluruh mengadopsi prinsipprinsip manajemen resiko yang melibatkan analisis ketidakpastian. Selain itu, proses ini memungkinkan penyediaan data yang dapat dikurangkan dari sumber eksternal, misalnya data kebakaran dari otoritas setempat.

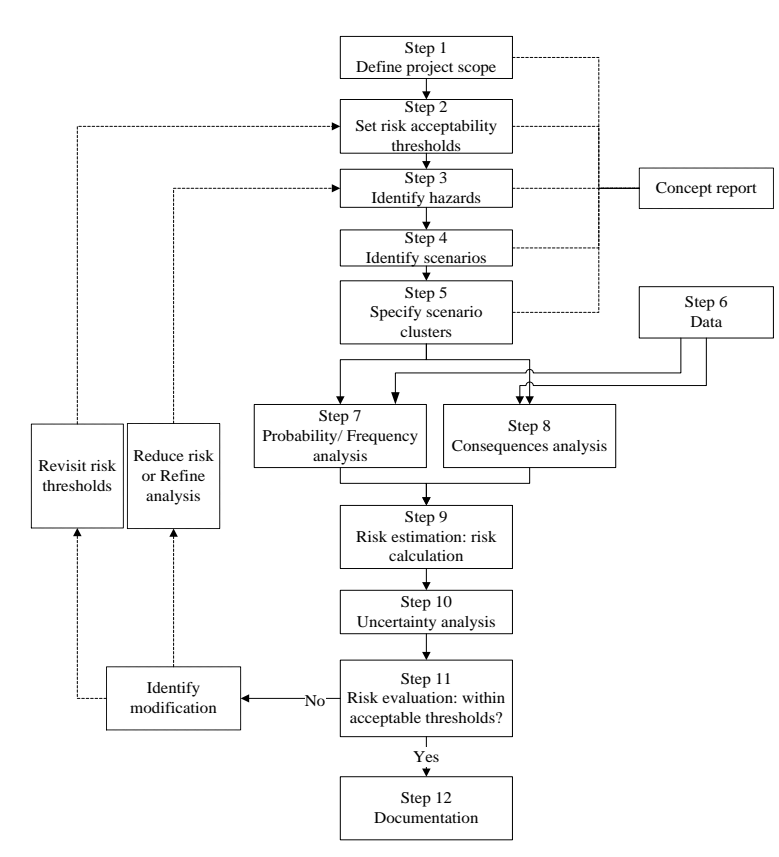

Gambar 2. Fire Risk Assessment Framework menurut SFPE (SFPE, 2005)

Kajian di atas menjelaskan bahwa fire safety framework ataupun fire risk assessment yang dibuat oleh berbagai organisasi internasional berguna untuk mendukung fire engineer dan pihak terkait dalam menentukan solusi keselamatan kebakaran bangunan. Sebagai dokumen teknis, prosedur tersebut mengadopsi prinsip manajemen resiko. Namun, perhatian utama diberikan pada pendekatan rekayasa engineering untuk memberikan langkah-langkah keselamatan kebakaran yang tepat di dalam gedung. Dengan demikian, perlu penekanan lebih dalam pada jenis tindakan kontrol yang bersifat reaktif, yang diperlukan saat kejadian kebakaran sudah terjadi, misalnya pemadaman, alarm asap, dan evakuasi penghuni. Panduan tersebut mengabaikan tindakan kontrol yang bersifat proaktif atau pencegahan akan terjadinya kebakaran.

Pada tahap operasional gedung, manajemen keselamatan kebakaran digunakan sebagai pedoman operasional dalam organisasi. Kegiatan manajemen keselamatan kebakaran 
bervariasi tergantung pada sistem manajemen operasional individu dalam organisasi.

Komponen manajemen keselamatan kebakaran diprakarsai oleh Malhotra pada tahun 1987 (Malhotra, 1987) dimana program manajemen keselamatan kebakaran diarahkan agar semua persyaratan atau kondisi fasilitas gedung untuk melarikan diri (evacuation) tetap terpelihara. Program manajemen juga mencakup fasilitas eksternal yang dapat menjadi ancaman bagi penghuni disaat kebakaran. Pada tahun 1993, manajemen keselamatan kebakaran diperkenalkan sebagai bagian dari persyaratan bangunan (building code) untuk gedung yang ditempati lebih dari 50 orang (Malhotra, 1993). Untuk memastikan bahwa setiap perubahan bangunan tidak akan mengabaikan efektivitas fitur konstruksi yang direncanakan selama tahap desain, manajemen keselamatan kebakaran terdiri dari komponen: panduan langkah pencegahan kebakaran; pemantauan terhadap panduan; pemeliharaan fasilitas proteksi kebakaran; pelatihan penghuni; latihan kebakaran dan rencana darurat.

Pada lingkup yang lebih luas, manajemen keselamatan kebakaran diperkenalkan di British Standard untuk bangunan publik dan kantor yang dilaksanakan di Inggris, BS 5588-12: 1999. kegiatan manajemen ini sebagian besar diadopsi pemerintah di Hong Kong (Chow, 2001a , Tsui dan Chow, 2004). Manajemen tersebut meliputi aspek teknis dan administratif, antara lain: rincian tanggung jawab manajemen; langkah-langkah komisioning instalasi keselamatan kebakaran dan manual keselamatan kebakaran; keberadaan personil keamanan kebakaran dan keamanan; program pelatihan staf dan penghuni; rancangan prosedur darurat dan evakuasi; panduan tindakan pencegahan kebakaran; dan program pemantauan dan evaluasi panduan keselamatan kebakaran, ekstensi dan perubahan. Komponen manajemen tersebut identik dengan manajemen keselamatan kebakaran diterapkan untuk operasinal terowongan bawah tanah di Hong Kong (Chow, 2001b).

Dari berbagai jenis aktivitas yang dilakukan dalam mengelola keselamatan kebakaran di atas, dapat disimpulkan bahwa keselamatan kebakaran harus melibatkan setidaknya 8 komponen (Chow, 2001a) antara lain:

1. Inspeksi.

2. Pendidikan dan Pelatihan.
3. Pemadaman kebakaran.

4. Layanan darurat.

5. Evaluasi potensi kebakaran.

6. Pencegahan kebakaran.

7. Laporan dan pencatatan.

8. Komunikasi

Di University of Reading, model tanggap bencana menakankan pada 5 komponen, meliputi: keberadaan organisasi dan pembagian tanggung jawab di dalam organisasi bencana tersebut, aspek penghuni bangunan, pelatihan kebakaran, asuransi, baik pada penghuni bangunan maupun fisik sarana prasaran gedung, serta perencanaan penanggulangan bencana. $\mathrm{Ke}$ lima komponen model saling terkait satu sama lain secara hierarki.

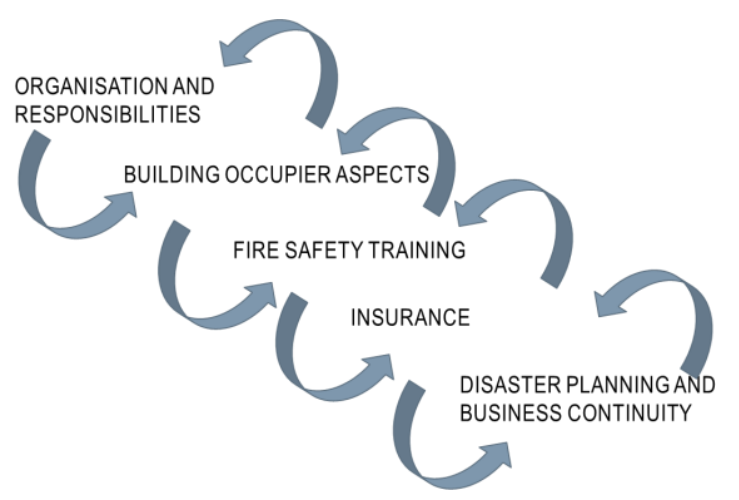

Gambar 3. Model Keselamatan Bangunan University of Reading - United Kingdom

University of Queensland menggunakan model tanggap bencana kebakaran dengan penekanan pada lima komponen untuk diimplementasikan baik pada saat perencanaan maupun operasional gedung. Komponen 1 adalah pemeliharaan sistim pemadaman, bertujuan menjamin gedung dan peralatan pemadaman dalam kondisi layak digunakan. Komponen 2 management personil petugas/ relawan kebakaran gedung yang menekankan pada mekanisme kerjasama, koordinasi, pelatihan dan pengarsipan dair masing masing relawan kebakaran gedung tersebut. Komponen 3, program pelatihan evakuasi gedung yang dilakukan setiap tahunnya. Komponen 4 berisi program pemantauan keselamatan kebakaran dan resiko yang secara teratur dilakukan setiap tahun. Sedangkan komponen 5 adalah rancangan gedung dan pengawasan penggunaannya. 


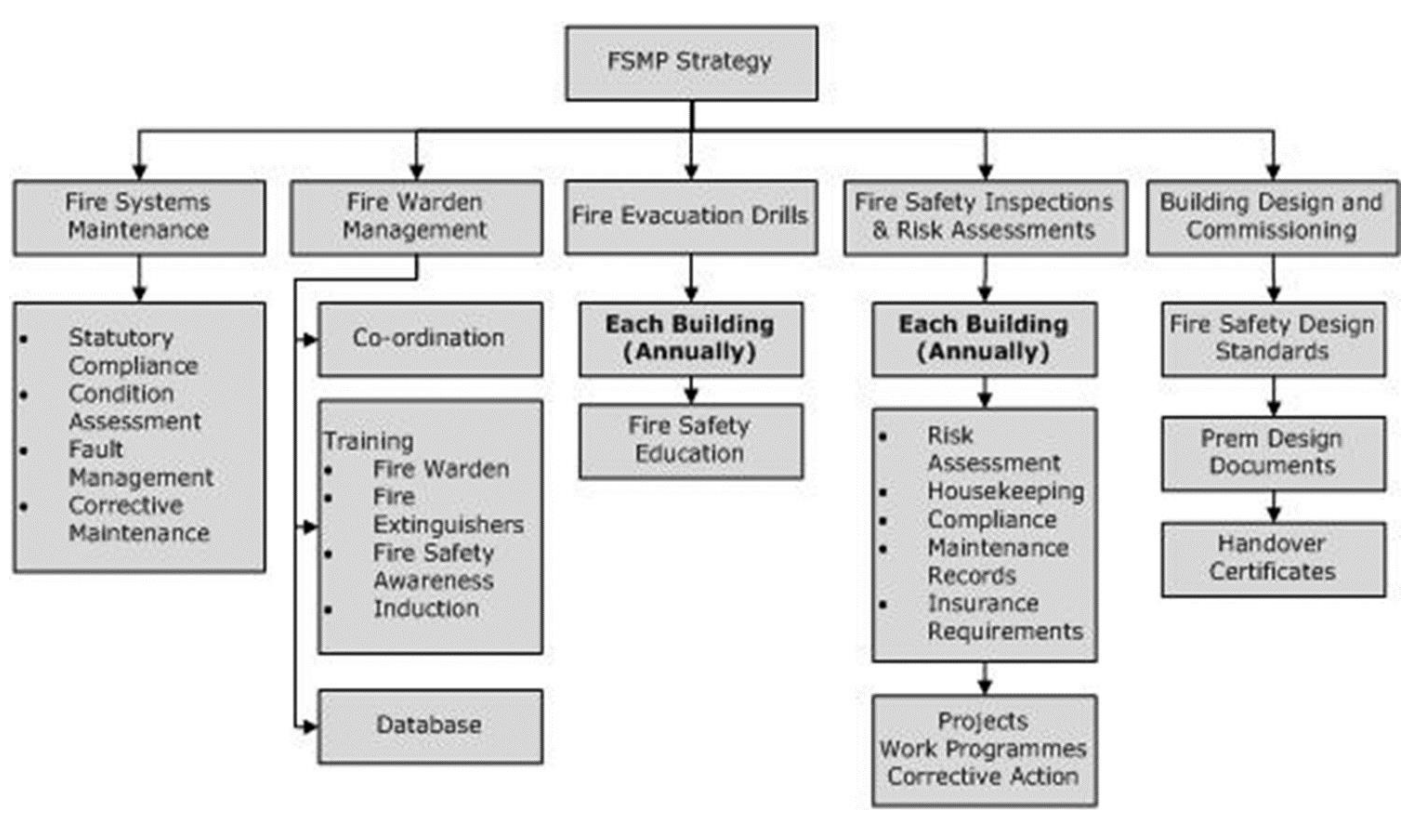

Gambar 4. Model Manajemen Keselamatan Bangunan University of Queensland - Australia

Disamping faktor teknologi bangunan dan manajemen pengelola, faktor perilaku manusia selalu menjadi bagian penting untuk dikaji (Hanford, 2008; Sufianto \& Green, 2012). Hal ini disebabkan keberagaman perilaku cenderung berpengaruh terhadap keselamatan penghuni pada saat terjadinya kebakaran (Meacham, 1999). Beberapa studi menemukan bahwa interpretasi penghuni terhadap keadaan sebelum alarm gedung bekerja berpengaruh terhadap waktu evakuasi penghuni secara keseluruhan (S. Gwynne, Purser, Boswell, \& Sekizawa, 2012; Guylene Proulx \& Reid, 2006).

Perilaku penghuni bangunan merupakan satu dari 3 kunci keberhasilan penanganan kebakaran (Kobes, Helsloot, de Vries, \& Post, 2010; Nilsson \& Johansson, 2009), dimana perilaku tersebut dipengaruhi oleh performance individual penghuni, karakter sosial, dan situasi saat kebakaran terjadi. Faktor perilaku penghuni juga dianggap sebagai penentu efektifitas kinerja peralatan pemadaman kebakaran yang ada di dalam bangunan (Bruck \& Thomas, 2010) dan kinerja sistim alarm bangunan (Filippidis, Galea, Gwynne, \& Lawrence, 2006; S. M. V. Gwynne, Boswell, \& Proulx, 2009).

\section{METODE}

Studi ini diarahkan untuk mengaudit kondisi fisik dan prasarana gedung serta perilaku penghuni bangunan terhadap bahaya kebakaran. Informasi fisik dan prasarana dikumpulkan melalui observasi lapangan, meliputi: pintu darurat, tangga kebakaran, sarana pemadaman kebakaran gedung, jaringan listrik, jarak antar bangunan, aksesibilitas gedung, ruang terbuka, sumber air dan tata letak hydrant. Sebelas gedung bertingkat dipilih sebagai sample penelitian.

Data perilaku dan persepsi penghuni terhadap keselamatan kebakaran didapatkan melalui angket kuestioner yang dilakukan secara online dan terbuka bagi seluruh civitas akademika Universitas Brawijaya. Pilot studi dilakukan untuk memastikan partisipan dapat mengisi dengan baik dan benar. 37 pernyataan dengan pilihan jawaban (Likert scale) diberikan kepada partisipan. Pertanyaan tersebut dikelompokkan kedalam enam kelompok, antara lain:

1. Pengetahuan dan kesadaran penghuni akan keselamatan kebakaran

2. Kepedulian terhadap kelengkapan saranaprasarana kebakaran gedung 
3. Kepedulian penghuni terhadap modifikasi ruang

4. Faktor untuk peningkatan keselamatan kebakaran

5. Media komunikasi keselamatan kebakaran

6. Manajemen pengelolaan gedung

Data audit fisik bangunan dan lingkungan dianalisa berdasarkan ketentuan teknis didalam Kepmeneg PU No. 10/2000 dan No. 11/2000 perihal petunjuk teknis keselamatan bangunan gedung. Sedangkan isian angket dianalisa secara statistik untuk mengetahui kecenderungan keberpihakan penghuni terhadap beberapa pernyataan yang diberikan.

\section{Model Tanggap Bencana Kebakaran Kampus}

Analisis dari data yang terkumpul baik dari wawancara, kuestioner penghuni maupun observasi fisik di lingkungan kampus UB, menunjukkan bahwa:

1. Kepedulian penghuni bangunan terhadap hal-hal penyebab timbulnya kebakaran relatif rendah.

2. Penghuni memiliki tingkat pemahaman berbeda terhadap tindakan darurat kebakaran

3. Kelengkapan serta kelayakan kinerja peralatan pendeteksian dan pemadaman relatif rendah

4. Lemahnya sistim pemeliharaan sarana dan prasarana gedung

5. Kualitas perangkat dan instalasi listrik bangunan belum sepenuhnya terjamin

6. Kelaikan jalur evakuasi pada beberapa gedung masih bermasalah.
7. Belum tersedianya guideline/ manual prosedur penggunaan peralatan fire protection maupun evakuasi

8. Belum tersedianya organisasi/ manajemen penanganan darurat kebakaran

9. Sistim insentif diterima oleh mayoritas penghuni gedung.

Kondisi eksisting tersebut memicu penyusunan langkah-langkah (intervensi) strategis yang bila dilakukan diharapkan akan terjadi peningkatan kondisi eksisting tersebut. Beberapa intervensi yang dapat dilakukan antara lain:

1. Perlunya peningkatan pendidikan dan pengetahuan penghuni dan pengelola gedung tentang sebab dan akibat kebakaran

2. Peningkatan pengetahuan dan ketrampilan akan pencegahan kebakaran

3. Ketrampilan evakuasi gedung secara aman

4. Pemeliharaan rutin terhadap insfrastruktur gedung, peralatan kelistrikan dan elektronik

5. Mengembalikan fungsi ruangan dan fasilitas gedung sesuai dengan ketentuan yang berlaku, khususnya fasilitas tangga darurat.

6. Pengembangan stadrad, manual prosedur ataupun panduan teknis akan operasional, pemeliharaan sarana-prasarana gedung dan evakuasi gedung.

7. Pengadaan struktur organisasi darurat kebakaran gedung

8. Pemberian insentif

9. Penerapan sanksi

Interfensi tersebut mengarahkan pembentukan komponen penting yang harus diwadahi dalam framework keselamatan kebakaran kampus UB (Gambar 5).

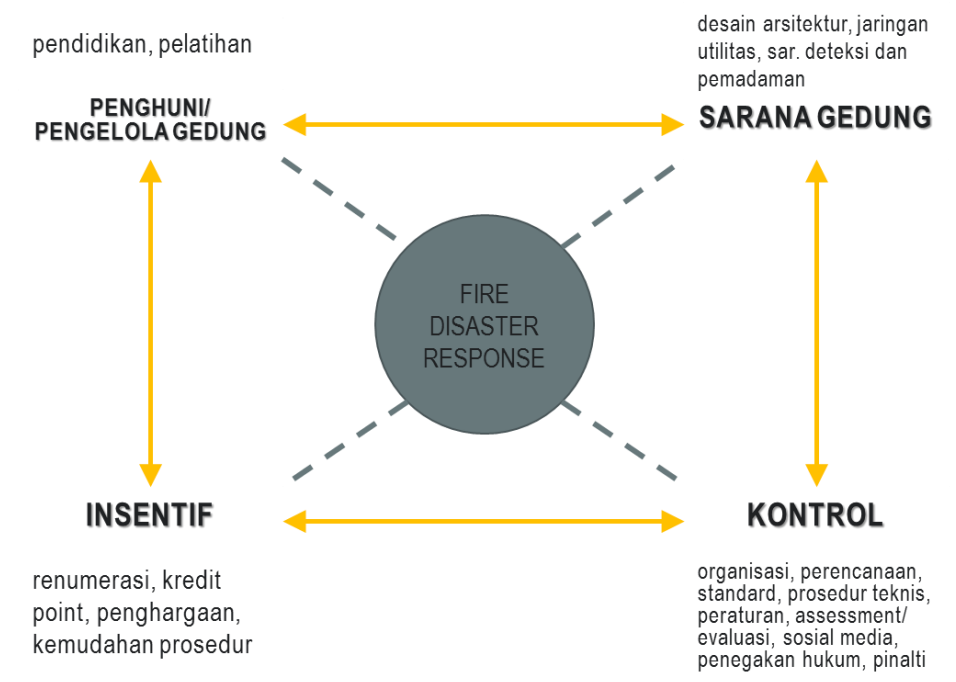

Gambar 5. Usulan Model Tanggap Bencana Kebakaran 
Model tanggap bencana kebakaran disusun terdiri dari empat komponen utama meliputi Penghuni/ pengelola gedung, sarana gedung, insentif dan kontrol. Keempat komponen tersebut bekerja bersama dan saling terkait mendukung dan mempengaruhi. Penghuni dan pengelola gedung perlu meningkatkan pendidikan dan pengetahuan tentang kebakaran, sehingga menimbulkan kepedulian diantara mereka, Insentif berperan menstimulasi penghuni dan pengelola gedung untuk meningkatan pendidikan dan ketrampilan. Insentif juga berperan dalam peningkatan kualitas sarana gedung baik dari sisi rancangan desian arsitektural, kelaikan sistim jaringan utilitas maupun sarana deteksi dan pemadaman gedung. Sarana gedung harus direncanakan dengan baik terutama sarana dan prasarana pendukung keamana kebakaran, terkontrol dan terpelihara dalam keadaan prima untuk mengeliminir kegagalan sistim bangunan. Sistim Kontrol yang akurat yang diimplementasikan secara professional dan konsisten diperlukan agar program peningkatan kepedulian penghuni, insentif dan sarana fisik gedung dapat berjalan dan senantiasa terpelihara dengan baik.

\section{KESIMPULAN}

Beberapa kesimpulan umum yang didapat dari hasil analisa dan pembahasan, antara lain:

1. Sarana penyelamatan gedung bertingkat kampus UB kurang memenuhi persyaratan seperti yang digariskan dalam standar bangunan bertingkat tinggi. Tata letak, konstruksi tangga darurat belum sesuai dengan ketentuan sehingga dapat mengancam kelancaran proses evakuasi.

2. Sistim managemen kebakaran belum sepenuhnya terdapat diseluruh gedung bertingkat, hanya sebagian kecil yang sudah memiliki upaya penunjukkan personel tertentu untuk pemadamam kebakaran, namun secara formal tidak dijumpai kelembagaan ataupun keorganisasian yang khusus menangani upaya pencegahan dan pemadaman kebakaran gedung kampus.

3. Tata masa bangunan kampus mampu mewadahi kebutuhan tempat berkumpul saat proses evakuasi penghuni, namun entrance gate kampus perlu dimodifikasi lebih lebar untuk memudahkan akses kendaraan damkar.

4. Keberadaan sarana hydrant halaman dan sumber air perlu ditingkatkan dilingkungan sekitar kampus sedemikian rupa sehingga dapat melayani setiap sudut bangunan tinggi.

5. Tingkat kesadaran individual penghuni bangunan terhadap potensi sumber api dinilai relatif rendah, mereka (terutama mahasiswa) kurang berminat untuk secara aktif terlibat dalam upaya peningkatan kewaspadaan dini kebakaran.

6. Penghuni bangunan pada umumnya tidak mempertimbangkan aspek keselamatan hunian pada saat melakukan perubahan/ modifikasi fungsi ruang.

7. Pemberian insentif dapat mempengaruhi perilaku penghuni bangunan dalam peningkatan pengetahuan keselamatan kebakaran gedung.

8. Aspek keselamatan bangunan harus dipertimbangkan sejak tahap perencanaan hingga operasional bangunan dengan memperhatikan sarana pemadaman dan kualitas peralatan listrik elektronik yang digunakan.

9. Promosi keselamatan kebakaran kampus dapat dilakukan melalui media informasi popular di kalangan penghuni dan berbagai program kegiatan organisasional kampus

\section{Daftar Pustaka}

Home Structure Fires (2011).

Bruck, D., \& Thomas, I. (2010) Interactions Between Human Behaviour and Technology: Implications for Fire Safety Science. Fire Technology, 46(4), 769-787. doi: 10.1007/s10694-010-0161-1

Chen, Ying-Yueh, Chuang, Ying-Ji, Huang, Chin-Hsing, Lin, Ching-Yuan, \& Chien, Shen-Wen. (2012). The adoption of fire safety management for upgrading the fire safety level of existing hotel buildings. Building and Environment, 51(0), 311-319.

Filippidis, L., Galea, E. R., Gwynne, S., \& Lawrence, P. J. (2006). Representing the influence of signage on evacuation behavior 
within an evacuation model. Journal of Fire Protection Engineering, 16(1), 37(37).

Gwynne, S.M.V., Boswell, D.L., \& Proulx, G. (2009). Understanding the Effectiveness of Notification Technologies in Assisting Vulnerable Populations. Journal of Fire Protection Engineering, 19(1), 31-49. doi: 10.1177/1042391508095094

Gwynne, SMV, Purser, DA, Boswell, DL, \& Sekizawa, A. (2012). Understanding and representing staff pre-warning delay. Journal of Fire Protection Engineering, 22(2), 77-99. doi: $10.1177 / 1042391512436785$

Hanford, Desiree J. (2008). The Human Factor Building Operating Management (Vol. 55, pp. 57-62): ABI/INFORM Trade \& Industry.

Hassanain, Mohammad A., \& Mohammed Abdul, Hafeez. (2005). Fire safety evaluation of restaurant facilities. Structural Survey, 23(4), 298-309.

Kobes, Margrethe, Helsloot, Ira, de Vries, Bauke, \& Post, Jos G. (2010). Building Safety and Human Behaviour in Fire: A Literature Review. Fire Safety Journal, 45(1), 1-11.

Malhotra, H. L. (1993). Proposed Code for Fire Safety in Buildings for the State of Sao Paulo: British Consulate, Sao Paulo- Brazil.

Meacham, B. J. (1999). Integrating Human Behavior and Response Issues Into Fire Safety Management of Facilities. Facilities, 17(9/10), 303-312. doi: $10.1108 / 02632779910278719$

Nilsson, Daniel, \& Johansson, Anders. (2009). Social Influence During the Initial Phase of a Fire Evacuation--Analysis of Evacuation Experiments in a Cinema Theatre. Fire Safety Journal, 44(1), 71-79.

Proulx, G. (2000). Why Building Occupants Ignore Fire Alarms: Institute for Research in Construction.

Proulx, Guylene, \& Reid, Irene M. A. (2006). Occupant Behavior and Evacuation during the Chicago Cook County Administration Building Fire. Journal of Fire Protection Engineering, 16(4), 283-309. doi: $10.1177 / 1042391506065951$

Sekizawa, A., Ebihara, M., Notake, H., Kubota, K., Nakano, M., Ohmiya, Y., \& Kaneko, H. (1999). Occupants' Behaviour in Response to the High-rise Apartments Fire in Hiroshima City. Fire and Materials, 23(6), 297-303.

Sufianto, Heru. (2013). A Fire Safety Improvement Framework for Residential Buildings: A Socio-Ecological Behaviour Modification Approach. (PhD), University of New South Wales, Sydney.

Sufianto, Heru, \& Green, AnthonyR. (2012). Urban Fire Situation in Indonesia. Fire Technology, 48(2), 367-387. doi: 10.1007/s10694-011-0226-9 